Tropical Journal of Pharmaceutical Research July 2017; 16 (7): 1481-1487

ISSN: 1596-5996 (print); 1596-9827 (electronic)

(C) Pharmacotherapy Group, Faculty of Pharmacy, University of Benin, Benin City, 300001 Nigeria.

All rights reserved.

Available online at http://www.tjpr.org

Original Research Article

http://dx.doi.org/10.4314/tjpr.v16i7.4

\title{
Preparation and assessment of ketamine hydrogels for prolonged transdermal anaesthesia
}

\author{
Mingsheng Liu* and Xiaoyu Zheng \\ Department of Anesthesiology, Fuzhou General Hospital of People's Liberation Army, Fuzhou, Fujian 350025 China
}

*For correspondence: Email: mingshengliu1974@hotmail.com; Tel/Fax: 0086-139-60778016

Sent for review: 15 December 2016

Revised accepted: 15 June 2017

\begin{abstract}
Purpose: To formulate and assess thermoresponsive ketamine hydrogels for prolonged transdermal analgesia/anaesthesia.

Methods: Thermoresponsive ketamine hydrogels were prepared from chitosan (CTS) and poloxamer 407. Four different formulations (2 formulations of ketamine with 1 and $2 \% w / w$ CTS and 2 formulations with 10 and $15 \%$ w/w ploxamer 407) were assessed for $\mathrm{pH}$, spreadability, drug content, viscosity, in vitro permeation/diffusion, in vivo skin irritancy, and in vivo analgesia (using the hot plate/writhing method in Wistar rats).

Results: The formulations had a high drug content (96.12 \pm 1.24 to $98.49 \pm 0.07 \%$ ) with good spreadability. They showed prolonged drug release/permeation of ketamine across the skin, ranging from 81.23 to $98.28 \%$, and were non-irritating to the denuded skin of Wistar rats with no erythema or oedema after $24 \mathrm{~h}$. The preparation showed effective analgesia that lasted 24 to $30 \mathrm{~h}$. In the writhing test, CTS hydrogels showed stronger analgesia (60.26 - 58.97\%) than those made with poloxamerbased hydrogels (56.41 and $53.85 \%$ ). Compared to the activity shown by the standard, lidocaine (which produced $62.82 \%$ analgesia), the effect of the test formulations seem good for probable therapeutic use. Using the hot plate method, the poloxamer-based hydrogels showed more prolonged analgesia than the CTS-based hydrogels.

Conclusion: Ketamine hydrogels of CTS and poloxamer may be useful for prolonged analgesia in neuropathic pain and local anaesthesia in minor surgeries.
\end{abstract}

Keywords: Ketamine, Chitosan, Poloxamer, Thermoresponsive hydrogel, Transdermal, Skin permeation

Tropical Journal of Pharmaceutical Research is indexed by Science Citation Index (SciSearch), Scopus, International Pharmaceutical Abstract, Chemical Abstracts, Embase, Index Copernicus, EBSCO, African Index Medicus, JournalSeek, Journal Citation Reports/Science Edition, Directory of Open Access Journals (DOAJ), African Journal Online, Bioline International, Open-J-Gate and Pharmacy Abstracts

\section{INTRODUCTION}

Anaesthesia is a vital requirement for surgery. Unlike major surgeries that require general anaesthesia, minor surgeries are often performed under local anaesthesia. Transdermal (i.e., through the skin) anaesthesia may be a good alternative to local blocks for minor surgeries. Transdermal anaesthesia is of potential benefit postoperatively, particularly in paediatric and elderly patients. Transdermal anaesthetic agents are available as a patch, film, gel, or cream [1-3].

Transdermal anaesthesia has been used for more than three decades in children following invasive procedures [1-3]. Transdermal anaesthetics must have a rapid onset of action with good efficacy at a low cost. Many studies have explored the transdermal administration of anaesthetic drugs in various forms that allow rapid absorption (irrespective of molecular weight and skin permeability) with consistent efficacy 
$[2,3]$. Various polymers such as polyglycolic acid, poly I-lactic acid, polylactic copolymer, chitosan (CTS), and poloxamerhave been investigated for the development of hydrogels. In this study, CTS and poloxamer were selected due to their relative ease of conversion to thermoresponsive hydrogels [4].

Ketamine (a phencyclidine derivative) is a noncompetitive antagonist of the $\mathrm{N}$-methyl D-aspartic acid receptor that interacts with cholinergic opioid receptors, purinergic receptors, and adrenoreceptors yielding local anaesthetic effects [5]. It is indicated for dissociative general anaesthesia and analgesia for neuropathic pain. Although not widely used, it has several unique clinical properties that make it appropriate in certain situations. Ketamine may be administered in a topical gel for peripheral action (at opioid and sodium-potassium receptors) [6], and can also be administered intravenously, although this route is associated with side effects such as dizziness, nausea, nightmares, agitation, and hallucinations [7]. Topical and transdermal administration of ketamine have been investigated to avoid dizziness and nausea. Moreover, when the drug penetrates the skin, it acts directly on the small nerve fibres, achieving effective localised anaesthesia [8-11]. Transdermal ketamine has also been investigated as an anaesthetic for cosmetic and laser dermatology. Previous studies that investigated creams and gels of ketamine formulations, demonstrated reduced numerical pain scores of $53-100 \%$ on a $1-10$ pain intensity scale [12]. These results indicate that ketamine gel may be useful for cases of chronic neuropathic pain [12-16]. But the prior studies of topical ketamine did not compare the formulations prepared with different polymers. Therefore, this study assessed the analgaesic efficacy of ketamine hydrogels composed of two different polymers: CTS and poloxamer.

\section{EXPERIMENTAL}

\section{Materials}

Ketamine and CTS (from shrimp shells) were purchased from Sigma Aldrich (St. Louis, MO, USA). Poloxamer 407 was purchased from BASF (Ludwigshafen, Germany). The other chemicals were of analytical grade.

\section{Preparation of hydrogels}

The ketamine hydrogels were prepared from two polymers, poloxamer 407 and CTS (Table 1). To prepare the CTS hydrogel, CTS was dissolved in a $1 \%$ acetic acid solution while mixing at 300 rpm for $15 \mathrm{~min}$. Ketamine was mixed into the solution along with propylene glycol and triethanolamine until homogeneity was achieved. The poloxamer solution was prepared in precooled water, and ketamine was mixed into the solution along with propylene glycol and triethanolamine until it became slightly viscous. The $\mathrm{pH}$ was adjusted to 6.5 to reduce its tendency to cause skin irritation, and the slightly viscous hydrogel was stored at room temperature overnight to ensure the release all of their bubbles. The hydrogels were packed into aluminium tubes that were securely closed, and stored at room temperature until used.

Table 1: Composition of ketamine hydrogel

\begin{tabular}{lllll}
\hline Ingredient & \multicolumn{4}{c}{ Hydrogel formulation } \\
\cline { 2 - 5 }$(\% \mathbf{w} / \mathbf{w})$ & $\mathbf{H 1}$ & $\mathbf{H 2}$ & $\mathbf{H 3}$ & $\mathbf{H 4}$ \\
\hline Ketamine & 5 & 5 & 5 & 5 \\
Chitosan & 1 & 2 & - & - \\
Poloxamer 407 & - & - & 10 & 15 \\
Polyethylene Glycol & 10 & 10 & 10 & 10 \\
Triethanolamine & 0.1 & 0.1 & 0.1 & 0.1 \\
Distilled Water & Qs & Qs & qs & qs \\
\hline
\end{tabular}

\section{Physical assessment of hydrogels}

The hydrogels were assessed for colour, appearance, tactile feel upon application, consistency, texture, and $\mathrm{pH}$. Spreadability was also determined by sandwiching the gel between two glass plates and recording the movement of the top plate in response to a pulling force of 80 g. $\mathrm{pH}$ was determined using a digital $\mathrm{pH}$ meter.

\section{Rheology of hydrogels}

The viscosity values and rheological properties of the hydrogels were determined using a DV II + ProDigital Viscometer (Brookfield Engineering, Middleboro, MA, USA).

\section{Drug concentration}

From the vials of formulations, $1 \mathrm{~mL}$ of each sample was transferred to a volumetric flask using a micropipette. Methanol (up to $10 \mathrm{~mL}$ ) was added to this sample until complete precipitation (i.e., the supernatant became mostly clear). After centrifugation (1000 rpm for $20 \mathrm{~min}$ ), the clear supernatant was withdrawn, diluted, and analysed with a spectrophotometer at 276 $\mathrm{nm}$.

\section{Ex vivo drug diffusion studies}

Ex vivo drug diffusion was assessed using the abdominal skin of rats (pre-treated to remove hair and other fatty and connective tissues) with 
a Franz diffusion cell at $37 \pm 1.0^{\circ} \mathrm{C}$ in $12.5 \mathrm{~mL}$ phosphate buffer at $\mathrm{pH} 7.4$. The pre-treated rat abdominal skin was placed on the bottom opening of the donor compartment in contact with the receptor medium throughout the study; both compartments were tightly fastened with clamps. The receptor medium was agitated at 200 rpm by placing the apparatus on a magnetic stirrer on a hot plate for $24 \mathrm{~h}$, after which $1 \mathrm{~mL}$ of sample was removed at various time points and replaced with the same volume of fresh phosphate buffer $(\mathrm{pH} 7.4)$ at the same temperature. Each sample was analysed at 276 $\mathrm{nm}$ in an ultraviolet-visible spectrophotometer.

\section{In vitro release kinetic analysis}

The drug release kinetics was determined by inserting the obtained data into the following model equations to check for fit:

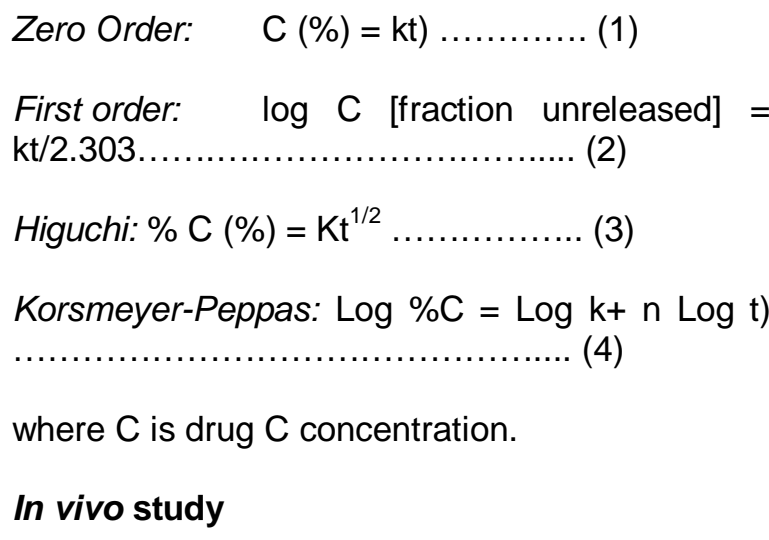

The study was conducted using healthy male Wistar rats $(200-280 \mathrm{~g})$. The rats were kept in standard housing and environmental conditions. Rats were given 3-4 days to acclimatise before the in vivo study. The rats were given free access to drinking water and a standard diet. The in vivo study protocol was approved by the Animal Ethical Committee (approval reference no. 299/2015). The study was conducted in compliance with the international guidelines on animal handling [17].

\section{Primary skin irritation studies}

The primary skin irritation test was conducted to check for side effects such as discomfort, erythaema, and oedema. Animals were divided into four groups $(n=3)$. A $2 \times 2$ cmarea of dorsal skin was denuded with a razor, and then wiped with alcohol. Four hours after denuding, a nonmedicated gel was applied to the skin of the rats in Group I (control group). Gel formulations H2 and $\mathrm{H} 4$ (with higher concentrations of CTS and poloxamer) were applied to Groups II and III. A standard irritant $(0.8 \% \mathrm{v} / \mathrm{v}$ aqueous solution of formaldehyde) was applied to Group IV (standard). After $24 \mathrm{~h}$, the application sites were scored for erythema and oedema [18].

\section{In vivo analgesic study}

\section{Writhing method}

Acute analgesia provided by the hydrogels was assessed using the writhing method (induced by acetic acid). The rats were divided into six groups $(n=6)$. The first group (control) received non-medicated hydrogel, the second group received standard analgesia (topical gel of lidocaine hydrochloride, $5 \mu \mathrm{g} / \mathrm{kg}$ body mass), and test groups $\mathrm{III}-\mathrm{VI}$ received $\mathrm{H} 1, \mathrm{H} 2, \mathrm{H} 3$, and $\mathrm{H} 4$ formulations (10 $\mu \mathrm{g} / \mathrm{kg}$ body mass), respectively. Three hours following application, writhing was induced using $10 \mathrm{~mL} / \mathrm{kg}$ acetic acid solution (0.6 $\% \mathrm{v} / \mathrm{v}$ ) injected intraperitoneally; the number of writhes in $20 \mathrm{~min}$ was recorded as the percentage reduction of writhing compared to the control group.

\section{Hot plate method}

The four test groups of rats were each administered an individual formulation. The control group received non-medicated gel and the standard group received lidocaine (topical 2 $\%$ gel, $5 \mu \mathrm{g} / \mathrm{kg}$ ). After $30 \mathrm{~min}$, the rats were placed on an analgesiometer at $50{ }^{\circ} \mathrm{C}$. The duration and maximum response were noted for each group.

\section{Statistical analysis}

All of the data are presented as mean \pm standard deviation (SD). One-way analysis of variance was used for statistical analysis with Origin 5 as the software. $P<0.05$ was considered statistically significant.

\section{RESULTS}

The ketamine hydrogels were thermoresponsive and gelled after heating. The gels showed good spreadability and were clear and transparent. The surface $\mathrm{pH}$ ranged from $6.5 \pm 0.01$ to $6.9 \pm$ 0.02 (Table 2).

Drug content was relatively high, ranging from $96.12 \pm 1.24$ to $98.49 \pm 0.07 \%$ for all the hydrogel formulations.

\section{Rheological properties}

The viscosity of the ketamine hydrogels showed pseudo-plastic rheology. The shear rate increased in direct proportion to the angular 
velocity in the pre-gelled formulations. A change in viscosity with angular velocity (shear stress) was observed (Figure 1).

Table 2: Physiochemical characteristics of ketamine hydrogels

\begin{tabular}{lcc}
\hline $\begin{array}{l}\text { Formulation } \\
\text { code }\end{array}$ & $\mathbf{p H}$ & $\begin{array}{c}\text { Drug } \\
\text { content (\%) }\end{array}$ \\
\hline $\mathrm{H} 1$ & $6.5 \pm 0.01$ & $97.14 \pm 1.06$ \\
$\mathrm{H} 2$ & $6.5 \pm 0.03$ & $96.12 \pm 1.24$ \\
$\mathrm{H} 3$ & $6.9 \pm 0.01$ & $98.02 \pm 0.42$ \\
$\mathrm{H} 4$ & $6.9 \pm 0.02$ & $98.49 \pm 0.07$ \\
\hline
\end{tabular}

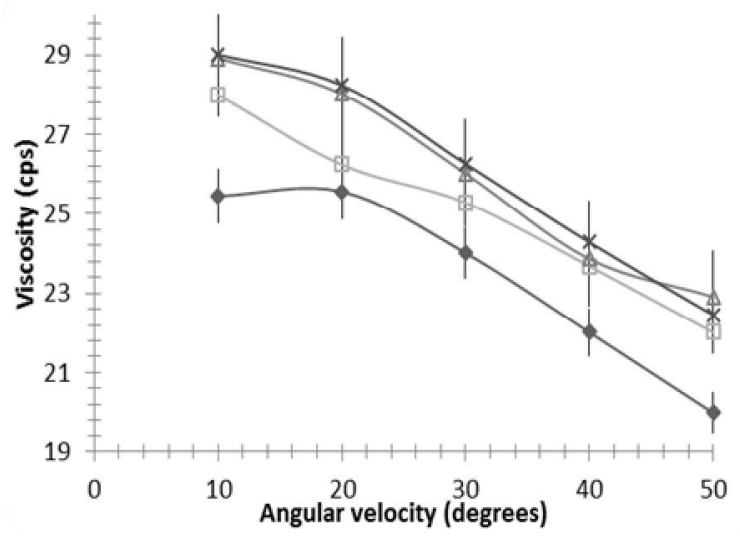

Figure 1: Viscosity of ketamine hydrogel formulations $\mathrm{H} 1(\bullet), \mathrm{H} 2(\square), \mathrm{H} 3(\Delta)$ and $\mathrm{H} 4(\times)$

At the angular velocity of $50^{\circ} \mathrm{C}$, the viscosities of the hydrogels were 19.99, 22.01, 22.91, and 22.45 cps for $\mathrm{H} 1, \mathrm{H} 2, \mathrm{H} 3$, and $\mathrm{H} 4$, respectively.

\section{In vitro diffusion/permeation}

The drug flux was constant and slow across the biomembrane. The hydrogels $\mathrm{H} 3$ and $\mathrm{H} 4$ showed the highest in vitro drug permeations across the membrane (Fig. 2).

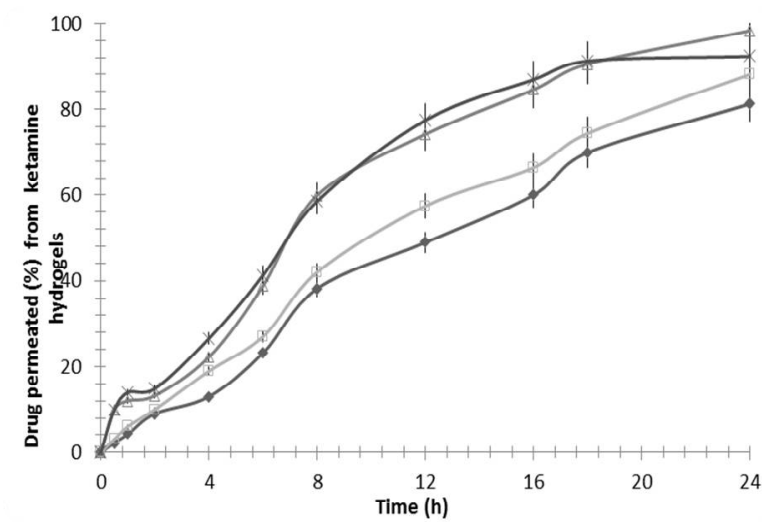

Figure 2: In vitro drug permeation of ketamine from hydrogels across rat abdominal skin. Note: $\mathrm{H} 1(\bullet), \mathrm{H} 2(\square), \mathrm{H} 3(\Delta)$ and $\mathrm{H} 4(\times)$
After $24 \mathrm{~h}$, drug permeation was 81.23, 88.04, 98.28 and $92.28 \%$ for $\mathrm{H} 1, \mathrm{H} 2, \mathrm{H} 3$, and $\mathrm{H} 4$, respectively. On subjecting the data to various pharmacokinetic models, all the hydrogels demonstrated Higuchi-type permeation. Matrix diffusion was seemed to be the main mechanism involved.

\section{Primary skin irritation}

No formulation showed any observable skin irritation. No side effects such as swelling or erythema were observed at the application site after $24 \mathrm{~h}$ (Table 3 ).

Table 3: Primary skin irritation test results for ketamine hydrogels

\begin{tabular}{lcc}
\hline \multirow{2}{*}{ Animal Group } & \multicolumn{2}{c}{ Mean \pm SD } \\
\cline { 2 - 3 } & Erythema $^{*}$ & Oedema $^{\star *}$ \\
\hline I Control & $0.67 \pm 0.58^{\mathrm{a}}$ & $0.34 \pm 0.58^{\mathrm{a}}$ \\
\hline II Test 1 (H2) & $0.67 \pm 0.58^{\mathrm{a}}$ & $0.34 \pm 0.58^{\mathrm{a}}$ \\
\hline III Test 2 (H4) & $0.67 \pm 0.58^{\mathrm{a}}$ & $0.34 \pm 0.58^{\mathrm{a}}$ \\
\hline $\begin{array}{l}\text { IV Standard } \\
\text { Irritant }\end{array}$ & $3 \pm 0$ & $1.67 \pm 0.50$
\end{tabular}

${ }^{a} P<0.05$, significant compared toformalin; *erythema scale: 0 , none; 1 , slight; 2, well defined; 3, moderate; 4, scar formation. **Oedema scale: 0 , none; 1 , slight;

2, well defined; 3 , moderate; 4 , severe

\section{In vivo analgesia}

The writhing results demonstrated that $\mathrm{H} 1$ and $\mathrm{H} 2$ had good analgesia with a percentage of 62.82 and $60.26 \%$, respectively (Table 4).

The hot plate method demonstrated that $\mathrm{H} 3$ and $\mathrm{H} 4$ (poloxamer-based hydrogels) yielded prolonged analgesia compared to that of $\mathrm{H} 1$ and H2 (Table 5).

Table 5: In vivo analgesic activity of ketamine hydrogels with the hot plate method

\begin{tabular}{lccc} 
Formulation & $\begin{array}{c}\text { MR } \\
(\mathbf{s})^{\mathbf{a}}\end{array}$ & $\begin{array}{c}\text { TMR } \\
(\mathbf{h})\end{array}$ & $\begin{array}{c}\text { DA } \\
(\mathbf{h})\end{array}$ \\
\hline $\mathrm{H} 1$ & $6.5 \pm 1.02$ & 1.12 & 9 \\
$\mathrm{H} 1$ & $7.5 \pm 1.20$ & 1.25 & $>9$ \\
$\mathrm{H} 3$ & $9.5 \pm 1.0$ & 2.50 & $>12$ \\
$\mathrm{H} 4$ & $10.5 \pm 1.2$ & $1.75 \quad>12$ \\
\hline${ }^{2}$ Data are expressed as mean \pm SEM $(n=6) ; \mathrm{M} R=$ \\
maximum analgesic response; TMR $=$ time of \\
maximum analgesic response; $D A=$ duration of \\
analgesic action
\end{tabular}


Table 4: In vivoanalgesic activity of ketamine hydrogels based on writhing method

\begin{tabular}{|c|c|c|c|}
\hline \multirow[t]{2}{*}{ Drug } & \multirow{2}{*}{$\begin{array}{c}\text { Dose } \\
(\mu \mathrm{g} / \mathrm{kg})\end{array}$} & \multicolumn{2}{|c|}{ Analgesicactivity } \\
\hline & & No. of writhes ${ }^{a}$ & Analgesia (\%) \\
\hline Control (blank films) & - & $78 \pm 1$ & - \\
\hline lidocaine (Standard) & 5 & $29 \pm 2^{b}$ & 62.82 \\
\hline $\mathrm{H} 1$ & 10 & $31 \pm 3^{b}$ & 60.26 \\
\hline $\mathrm{H} 2$ & 10 & $32 \pm 3^{b}$ & 58.97 \\
\hline $\mathrm{H} 3$ & 10 & $34 \pm 3^{b}$ & 56.41 \\
\hline $\mathrm{H} 4$ & 10 & $36 \pm 3^{b}$ & 53.85 \\
\hline
\end{tabular}

\section{DISCUSSION}

In a previous small scale clinical study, ketamine was administered to humans at a dose range of $0.093-9.33 \mathrm{mg} / \mathrm{kg}$ ) [12].Initial application provided significant pain relief to all of the patients. The average pain score decreased from 8.8 (pre-application) to 1.6 post-application (mean, $15 \mathrm{~min}$ ) [12]. The ketamine hydrogels investigated in this study were thermoresponsive, had good viscosity, and spread easily on the skin surface. The viscosity should be optimum for a gel in the sense that it should neither be too high nor be too low. The higher viscosity may lead to the stiff gel which would not be applicable properly onto the skin. On the other hand, the less viscous gel shall flow and not be retained onto the skin. In both the cases the drug release may get affected. In this aspect the prepared formulations showed desired viscosity with easy to spread property.

Poloxamer hydrogels yielded more effective analgesia than CTS-based hydrogels. In a previous study the phase transition temperature (Tsol-gel) and rheological properties of poloxamer 407 gel were evaluated [19]. Tsol-gel reduced (without compromising the gel strength) and pseudoplastic rheology was observed upon the addition of microparticles (or drug). Thus, a thermoreversible gel was obtained with a rheology suitable for application. In the present study, the easy sol gel transition might have contributed to the improved drug delivery by poloxamer based hydrogels. The $\mathrm{pH}$ was satisfactory for all of the formulations, but the $\mathrm{H} 2$ and $\mathrm{H} 4$ formulations (with higher concentrations of CTS and poloxamer) had the best permeation across the skin. Moreover, drug permeation across the skin followed the Higuchi kinetics which confirms that the drug diffused via the matrix diffusion process.

The poloxamer hydrogels showed better drug release across the skin in the present study. The nature of polymers governs the release profile. Unlike chitosan (a hydrophilic polymer), Poloxamer $407 \AA$ is an amphiphilic synthetic copolymer consisting of a hydrophobic poly (oxypropylene) (POP) block between two hydrophilic poly(oxyethylene) (POE) blocks. Due to their amphiphilic nature, poloxamer molecules can readily self-assemble to form micelles depending on the concentration and temperature, and the drug release can be improved from these micelles. The micellization makes it easy for the drug to pass through across the skin. The amphiphilic polymers (like poloxamer) pass better across the skin and hence show the better drug permeation across the skin.

The results also showed that different concentrations of polymers may differ in efficacy and duration of action. This might be due to the formation of different degrees of micellization with different concentration in case of poloxamers. On the other hand, in case of chitosan, the thickness of diffusional barrier of polymeric network varies with the concentration resulting in change in drug release or duration of action. These results indicate that the structure of the gel functioned as an increasingly resistant barrier to drug release as the concentration of chitosan increased [20]. Therefore, the concentration of polymers may be chosen or may be optimized for desired drug release.

The in vivo results showed that thermoresponsive hydrogels provided effective analgesia. CTS hydrogel formulations had quicker onset times but shorter durations of action compared to the poloxamer hydrogels. Topical and transdermal routes have also been investigated for the administration of other anaesthetic agents [21-25].

\section{CONCLUSION}

The findings of this study demonstrated that thermoresponsive ketamine hydrogels prepared using CTS and poloxamer 407 may provide effective analgesia in minor surgery and neuropathic pain. Furthermore, the concentration of polymer in the hydrogel may affect transdermal absorption of ketamine. 


\section{DECLARATIONS}

\section{Acknowledgement}

The authors would like to thank Fuzhou General Hospital for providing the necessary facilities to conduct this research.

\section{Conflict of Interest}

No conflict of interest associated with this work.

\section{Contribution of Authors}

The authors declare that this work was done by the authors named in this article and all liabilities pertaining to claims relating to the content of this article will be borne by them.

\section{Open Access}

This is an Open Access article that uses a funding model which does not charge readers or their institutions for access and distributed under the terms of the Creative Commons Attribution License (http://creativecommons.org/licenses/by/ 4.0) and the Budapest Open Access Initiative (http://www.budapestopenaccessinitiative.org/rea d), which permit unrestricted use, distribution, and reproduction in any medium, provided the original work is properly credited.

\section{REFERENCES}

1. Houck CS, Sethna NF. Transdermal analgesia with local anesthetics in children: Review, update and future directions. Expert Rev Neurother 2005; 5(5): 625-634.

2. Edward A. Shipton, New Formulations of Local Anaesthetics-Part I. Anesthesiol Res Pract 2012: Article ID 546409, http://dx.doi.org/10.1155/2012/ 546409

3. Nortier YL, van de Haven JA, Koks $\mathrm{CH}$, Beijnen $\mathrm{JH}$. Preparation and stability testing of a hydrogel for topical analgesia. Pharm World Sci 1995; 17(6): 214- 217.

4. Byeongmoon J, Sung $W K$, You HB. Thermosensitive sol-gel reversible hydrogels. Adv Drug Deliv Rev 2012; 64: 154-162.

5. Persson J. Wherefore ketamine? Curr Opin Anaesthesiol 2010; 23: 455-460.

6. Hirota K, Lambert DG. Ketamine: New uses for an old drug? Br J Anaesth 2011; 107: 123-126.

7. Madhuri S. Kurdi, Kaushic A. Theerth, and Radhika S. Deva, Ketamine: Current applications in anaesthesia, pain, and critical care. Anesth Essays Res 2014; 8(3): 283-290.
8. Rabi J. Topical Ketamtene: A review of the history, mechanisms, uses, safety, and future. Int $J$ Pharm Comp 2016; 20(2): 107-113.

9. Gong C, Qi T, Wei X, Qu Y,Wu Q, Luo F, Qian Z. Thermosensitive polymeric hydrogels as drug delivery systems. Curr Med Chem 2013; 20(1): 79-94.

10. Nnamani PO, FC Kenechukwu, $C L$ Anugwolu and $A A$ Attama. Evaluation of hydrogels based on Poloxamer 407 and polyacrylic acids for enhanced topical activity of Gentamicin against susceptible infections. Trop J Pharm Res 2014; 13 (9): 1385-1391.

11. Zapantis G, Csóka I, Csányi E, Horváth G, Erős I. Evaluation of ketamine systemic absorption from topical preparations, Acta Biologica Hungarica 2006; 57(3): 387-389.

12. Gammaitoni A, Gallagher RM, Welz-Bosna M. Topical ketamine gel: Possible role in treating neuropathic pain. Pain Med 2000; 1(1): 97-100.

13. Amin SP, Goldberg DJ. Topical anesthetics for cosmetic and laser dermatology. J Drugs Dermatol 2005; 4(4): 455-461.

14. Huang $W$, Vidimos A. Topical anesthetics in dermatology. J Am Acad Dermatol 2000; 43(2): 286-98.

15. Mercadante $S$. Topical amitriptyline and ketamine for the treatment of neuropathic pain. Expert Rev Neurother 2015; 15(11): 1249-1253

16. Mahoney JM, Topical ketamine cream in the treatment of painful diabetic neuropathy. J Am Podiatr Med Assoc 2012; 102(3): 178-183.

17. European Commission. Directive 2010/63/EU on the protection of animals used for scientific purposes [cited 2015 June 11]. Available from: http://ec.europa. eu/environment/chemicals/lab_animals/legislation_en.ht $m$.

18. Wang $Y$, Zhao Xiao-Ping, Ruan Jian-Wei. Transdermal drug delivery system of aceclofenac for rheumatoid arthritis and the effect of permeation enhancers: Invitro and in vivo characterization, Int $J$ Pharmacol 2015; 11(5): 456-462.

19. Pereira GG, Dimer FA, Guterres SS, Kechinski CP, Granada JE, Cardozo NSM. Formulation and characterization of poloxamer $407 \AA$ : thermoreversible gel containing polymeric microparticles and hyaluronic acid. Quím. Nova 2013;36(8): 10.1590/S010040422013000800008

20. Varshosaz J, Tabbakhian M, Salmani Z. Designing of a thermosensitive chitosan/poloxamer in situ gel for ocular delivery of ciprofloxacin. The Open Drug Deliv J, 2008; 2: 61-70

21. Song MS, Zhang WJ, Li J, Ma J. Transdermal drug delivery of lidocaine as patient compliant local anaesthesia in effective management of postoperative pain. J Biomater Tissue Eng 2015; 5: 499-503.

22. Bischoff JM, Petersen M, Uçeyler N, Sommer C, Kehlet $H$, Werner MU. Lidocaine patch (5\%) in treatment of persistent inguinal postherniorrhaphy pain: $A$ randomized, double-blind, placebo-controlled, crossover trial. Anesthesiol 2013; 19(6): 1444-1452.

Trop J Pharm Res, July 2017; 16(7): 1486 
23. Bai Y, Miller T, Tan M, Law LS, Gan TJ. Lidocaine patch for acute pain management: $A$ meta-analysis of prospective controlled trials. Curr Med Res Opin 2015; 31(3): 575-581.

24. Stahl J, Kietzmann M. The effects of chemical and physical penetration enhancers on the percutaneous permeation of lidocaine through equine skin. BMC Vet Res 2014; 10: 138-143.

25. Lin $H$, Zhang $Y$, Hou $M$, Wang $Y$. Transdermal local anaesthetic films of tetracaine in comparison to the conventional gel in effective management of pain. Int $\mathrm{J}$ Pharmacol 2016; 12: 669-674. 